\title{
Local dissemination of osteosarcoma observed after massage therapy: a case report
}

\author{
Shinji Miwa ${ }^{1,2^{*}}$ (D) Michi Kamei ${ }^{3}$, Satoru Yoshida ${ }^{3}$, Satoshi Yamada' ${ }^{1}$, Hisaki Aiba' ${ }^{1}$, Hiroyuki Tsuchiya ${ }^{2}$ and \\ Takanobu Otsuka
}

\begin{abstract}
Background: Limited evidence is available regarding the dissemination of tumor tissues due to compression during massage therapy, a routine procedure in patients with various symptoms in Asian countries.

Case presentation: A 12-year-old male presented at a massage clinic with pain and swelling of his left knee, which worsened the same night. Consistent with conventional osteosarcoma, radiography revealed cortical bone destruction, osteoblastic changes, and periosteal reactions. Magnetic resonance imaging revealed a tumor in the distal femur, an extraskeletal mass, and an infiltrative lesion in the intramuscular and neurovascular areas surrounding the distal femur; this was considered as hemorrhage and dissemination of the tumor tissue. ${ }^{18}$ Fluorinelabelled fluorodeoxyglucose-positron emission tomography and computed tomography revealed multiple metastases in the spine, liver, and lung. Consistent with osteosarcoma, histopathological examination revealed tumor cell proliferation with extensive pleomorphism and mitoses. Despite undergoing chemotherapy, radiation therapy, and hip disarticulation, the patient died due to multiple metastases 13 months after the initial diagnosis.

Conclusions: The present case suggests association of massage therapy with the local dissemination of tumor tissues, although influence of massage therapy on metastatic lesions remains unclear. Massage therapists should be aware of the possibility for dissemination of hidden malignancies due to the procedure.
\end{abstract}

Keywords: Osteosarcoma, Dissemination, Massage therapy

\section{Background}

Despite it being the most common primary malignancy of the bone in adolescents and young adults, the incidence of osteosarcoma is only 5-7 cases/million/year [1]. Standard treatment modalities for osteosarcoma include preoperative chemotherapy, tumor resection with surgical margin, and postoperative chemotherapy. Prior to the introduction of chemotherapy, long term survival rates were $<20 \%[2$, $3]$; however, chemotherapy has significantly improved outcomes [4-6]. The current 5-year survival rate in patients with osteosarcoma is approximately $60-70 \%[7,8]$. Furthermore, limb-sparing surgery has become the standard

\footnotetext{
*Correspondence: miwapoti@yahoo.co.jp

'Department of Orthopedic Surgery, Graduate School of Medical Science, Nagoya City University, Nagoya, Japan

${ }^{2}$ Department of Orthopedic Surgery, Graduate School of Medical Science,

Kanazawa University, Kanazawa, Japan

Full list of author information is available at the end of the article
}

surgical procedure since the introduction of chemotherapy, and $85-97 \%$ of patients with osteosarcoma have reportedly undergone limb-sparing surgery $[9,10]$.

Osteosarcoma most commonly affects the distal femur [11], and patients with osteosarcoma of the distal femur sometimes present with knee pain. The discrepancy between the lesion site and symptoms may lead to delayed diagnosis and inadequate treatments. Particularly in Asian countries, massage therapy is used for a variety of health-related purposes $[12,13]$. Patients with malignancies sometimes receive massage therapy to alleviate symptoms including pain, swelling, and numbness. On the other hand, compression of tumor tissue may cause infiltration and metastasis although there is no clear evidence to support this process. Here we present a case suggesting the influence of compression of osteosarcoma

(c) The Author(s). 2019 Open Access This article is distributed under the terms of the Creative Commons Attribution 4.0 International License (http://creativecommons.org/licenses/by/4.0/), which permits unrestricted use, distribution, and reproduction in any medium, provided you give appropriate credit to the original author(s) and the source, provide a link to the Creative Commons license, and indicate if changes were made. The Creative Commons Public Domain Dedication waiver (http://creativecommons.org/publicdomain/zero/1.0/) applies to the data made available in this article, unless otherwise stated. 
on local dissemination of tumor tissue and discuss the effect of massage on the clinical course of tumor lesions.

\section{Case presentation}

A 12-year-old male presented at a massage clinic with pain and swelling in his left knee, which worsened the same night. At the orthopedic clinic, radiography performed on the following day revealed cortical bone destruction, osteoblastic changes, and periosteal reactions, consistent with conventional osteosarcoma (Fig. 1). For further examination and treatment, the patient was referred to our hospital 5 days after the massage therapy. Magnetic resonance imaging (MRI) revealed iso-signal intensity on T1-weighted images and high-signal intensity on T2-weighted images of the left distal femur; it also revealed an extraskeletal mass (Fig. 2). Furthermore, MRI revealed diffuse signal alteration in the muscles and the neurovascular areas surrounding the lesion in the distal femur; hence, hemorrhage and dissemination of the tumor were considered (Fig. 2). Consistent with osteosarcoma, open biopsy followed by histopathological examination revealed tumor cell proliferation with extensive pleomorphism and mitoses (Fig. 3). Seventeen days after the massage therapy, computed tomography revealed multiple metastatic lesions in the lung and liver (Fig. 4). Thoracic MRI revealed multiple metastases in the thoracic spine (Fig. 5). ${ }^{18}$ Fluorine-labeled fluorodeoxyglucosepositron emission tomography revealed tumor metastasis in the femur and multiple metastases in the thoracic and lumbar spine, liver, and pelvis (Fig. 6). The patient underwent chemotherapy comprising ifosfamide, carboplatin, pirarubicin, etoposide, doxorubicin, and methotrexate (Fig. 7). During the second course of chemotherapy, paraplegia due to spinal metastases developed and progressed. After eight courses of chemotherapy, the metastatic lesions in the lung and liver reduced in size (Fig. 8), although considerable

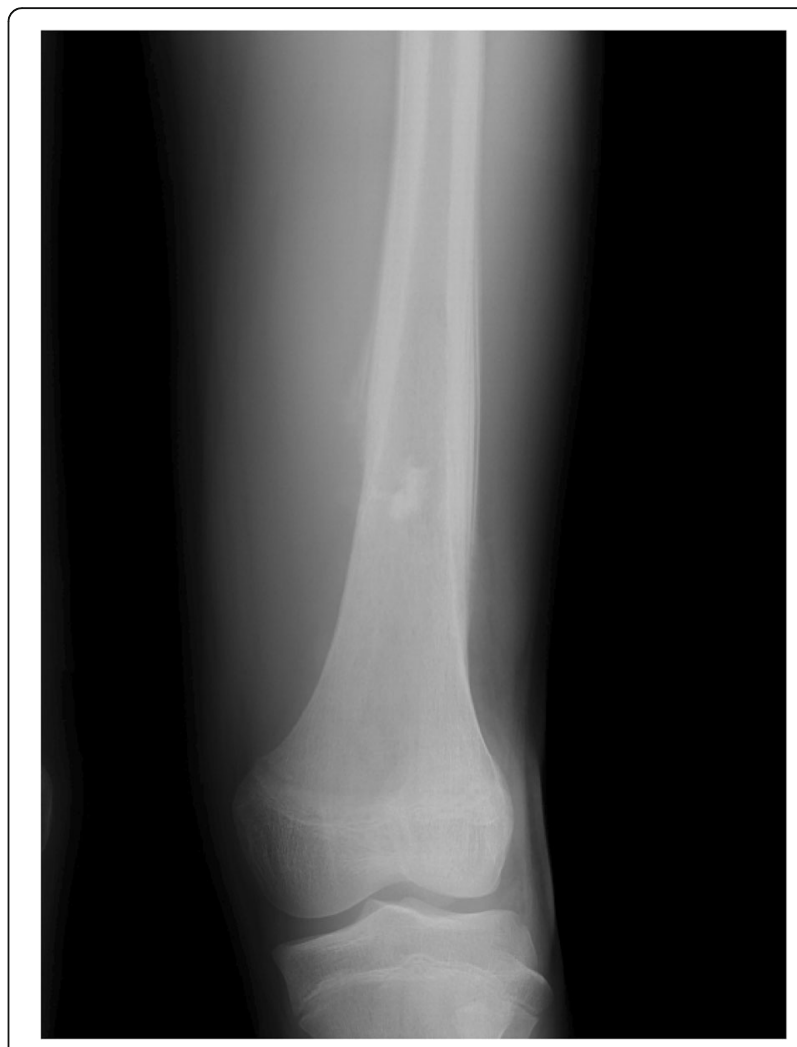

Fig. 1 Radiograph before chemotherapy. Sclerotic lesion with periosteal reaction was observed in the distal femur

primary tumor growth was observed (Fig. 9). Subsequently, the patient received hip disarticulation 6 months after the initial diagnosis, and he then underwent radiation therapy for metastatic lesions in the liver and sacrum. However, metastatic lesion growth was observed, and the patient died due to multiple metastases 13 months after the initial diagnosis.
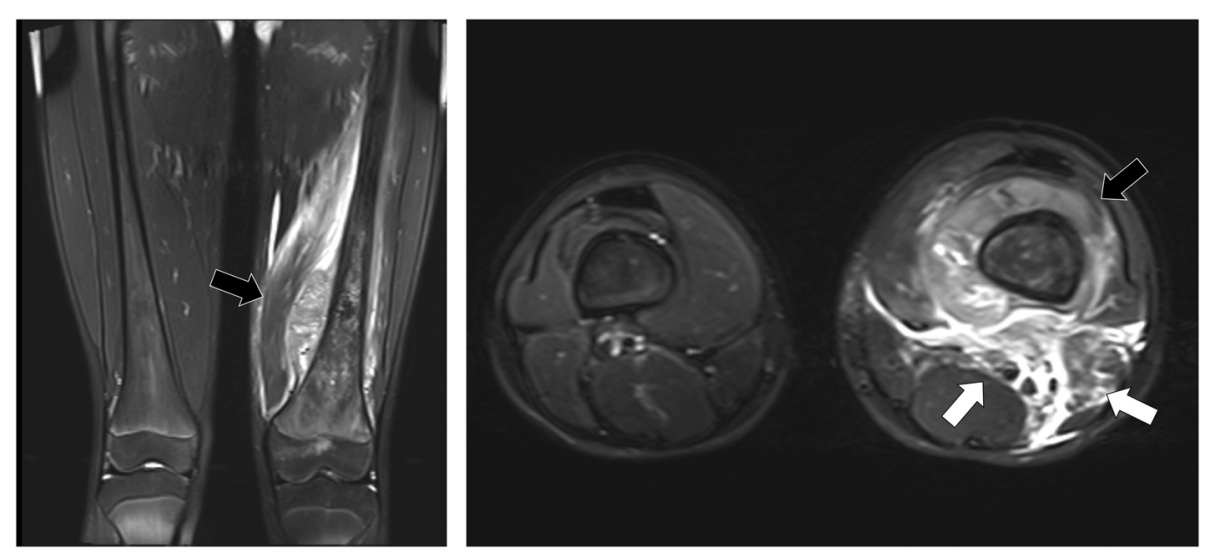

Fig. 2 Magnetic resonance imaging (MRI) prior to chemotherapy. MRI revealed extraskeletal mass of distal femur (black arrow), and a lesion thought to be hemorrhage and dissemination of tumor tissues (arrow) were observed 


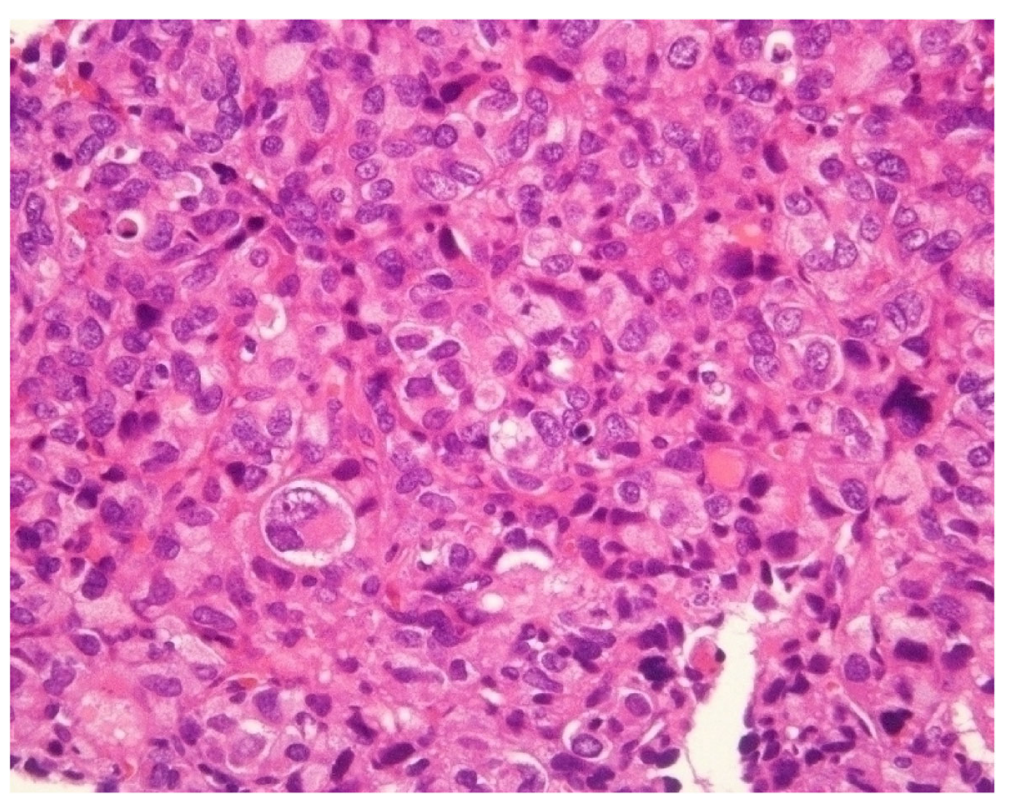

Fig. 3 Histology. Hematoxylin and eosin staining showed proliferation of tumor cells with extensive pleomorphism and mitoses, which was consistent with osteosarcoma

\section{Discussion and conclusions}

Despite the weak evidence regarding its efficacy, massage therapy is widely used to mitigate various types of chronic pain symptoms and to promote return to normal function [14-19]. Indeed, a randomized trial showed that therapeutic massage provides relief from intense pain, improves mood status, and offers muscle relaxation in patients with metastatic bone pain [20]. The possibility that direct compression of a tumor may induce metastasis and dissemination has been considered, although there is little evidence. Therefore, compression due to Esmarch's bandages and tourniquets are contraindications for tumors in the extremities [21, 22]. Hayashi et al. investigated the association of tumor compression and lymph node metastasis in a mouse model of fibrosarcoma [23]; in vivo fluorescence imaging of the fibrosarcoma cells labeled with a fluorescent protein showed that pressure-dependent compression of the tumor tissue increased the number of tumor cells that shed into the lymph duct. An in vivo study using GFP-labeled osteosarcoma cells demonstrated that massage increases tumor volume as well as metastases in the lymph node and lung [13].

In a retrospective study conducted in Taiwan, 70 of 134 patients (52\%) with osteosarcoma underwent alternative medical treatment including massage therapy before their initial visit to the hospital [12]. A remarkable difference was observed in the 5 -year overall survival rate- $58 \%$ in patients treated with massage therapy versus $92 \%$ in those not treated massage therapy. However, these results were confounded because prior to the hospital visit, there was a significantly higher incidence of metastatic lung lesions upon initial diagnosis (51\% in the massage group vs $19 \%$ in the non-massage group) and higher rate of tumor recurrence (29\% in the massage group vs $6 \%$ in the non-massage group). Another retrospective study showed that massage therapy decreased overall survival and increased incidence of local recurrence and metastases [13]. Thus, due to the
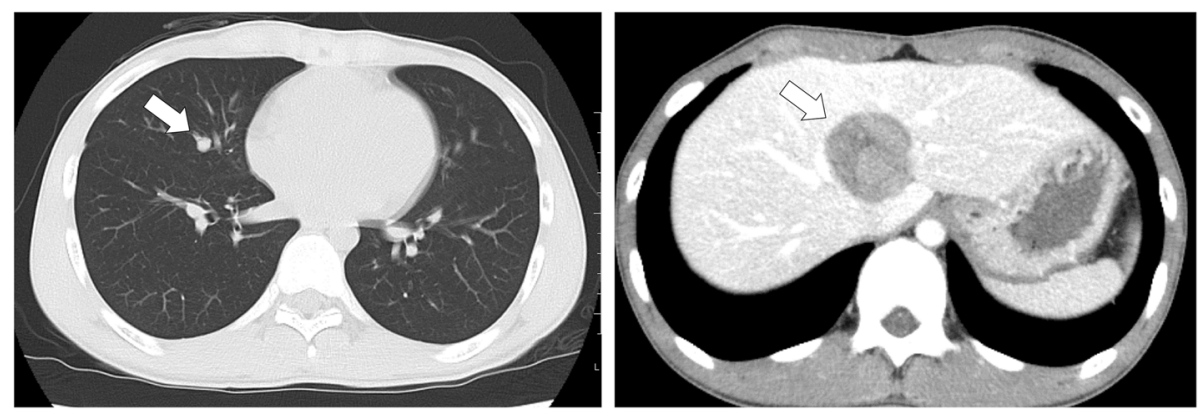

Fig. 4 Computed tomography (CT) prior to chemotherapy. Metastatic lesions in the lung and liver were observed (arrow) 


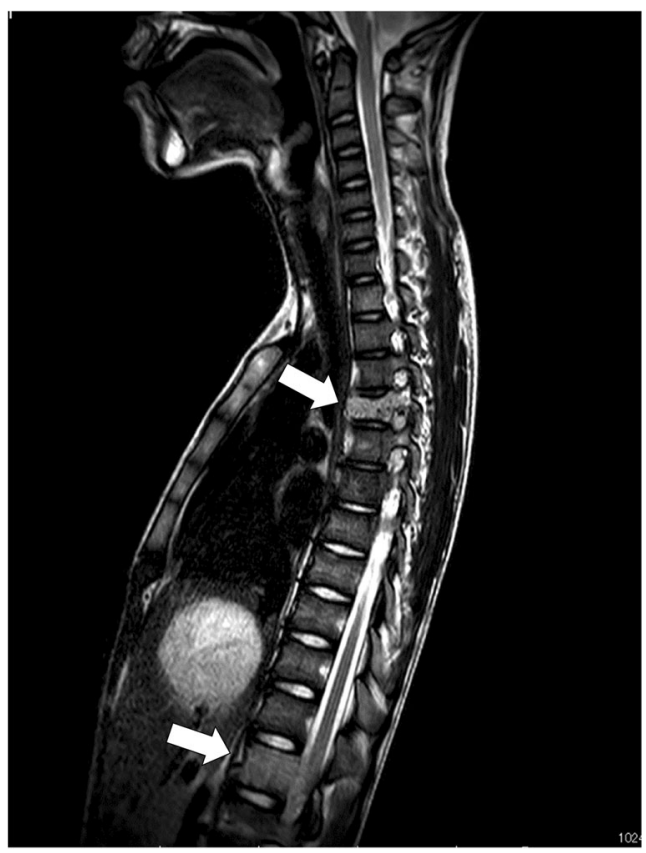

Fig. 5 Magnetic resonance imaging. Metastases were observed at the Th4 and Th 12 vertebrae (arrow) fragility of the tumor tissue compared with normal tissue, compression during massage is thought to destroy tissues and rupture tumor vessels. Dissemination of tumor tissue due to hemorrhage renders it difficult to perform limb salvage surgery, thereby impacting survival. In the present case, the association of massage therapy with the dissemination of osteosarcoma cannot be determined because lack of MRI before massage therapy. However, the diffuse signal alteration in the muscles and the neurovascular areas surrounding the tumor observed by MRI is consistent with a cause of the severe pain after massage therapy. Therefore, the present case suggests the local dissemination of tumor tissue due to compression of the osteosarcoma, although the influence of massage therapy on metastatic disease remains unclear. Although massage therapy alleviates several symptoms and brings relief, massage therapists should be aware of the possibility that their massage can disseminate hidden malignancies. In conclusion, the present case suggests the dissemination of tumor tissue due to massage therapy, which while creating awareness regarding this rare but most common malignant bone tumor in youth also cautions massage therapists to be aware of the condition and the outcomes.

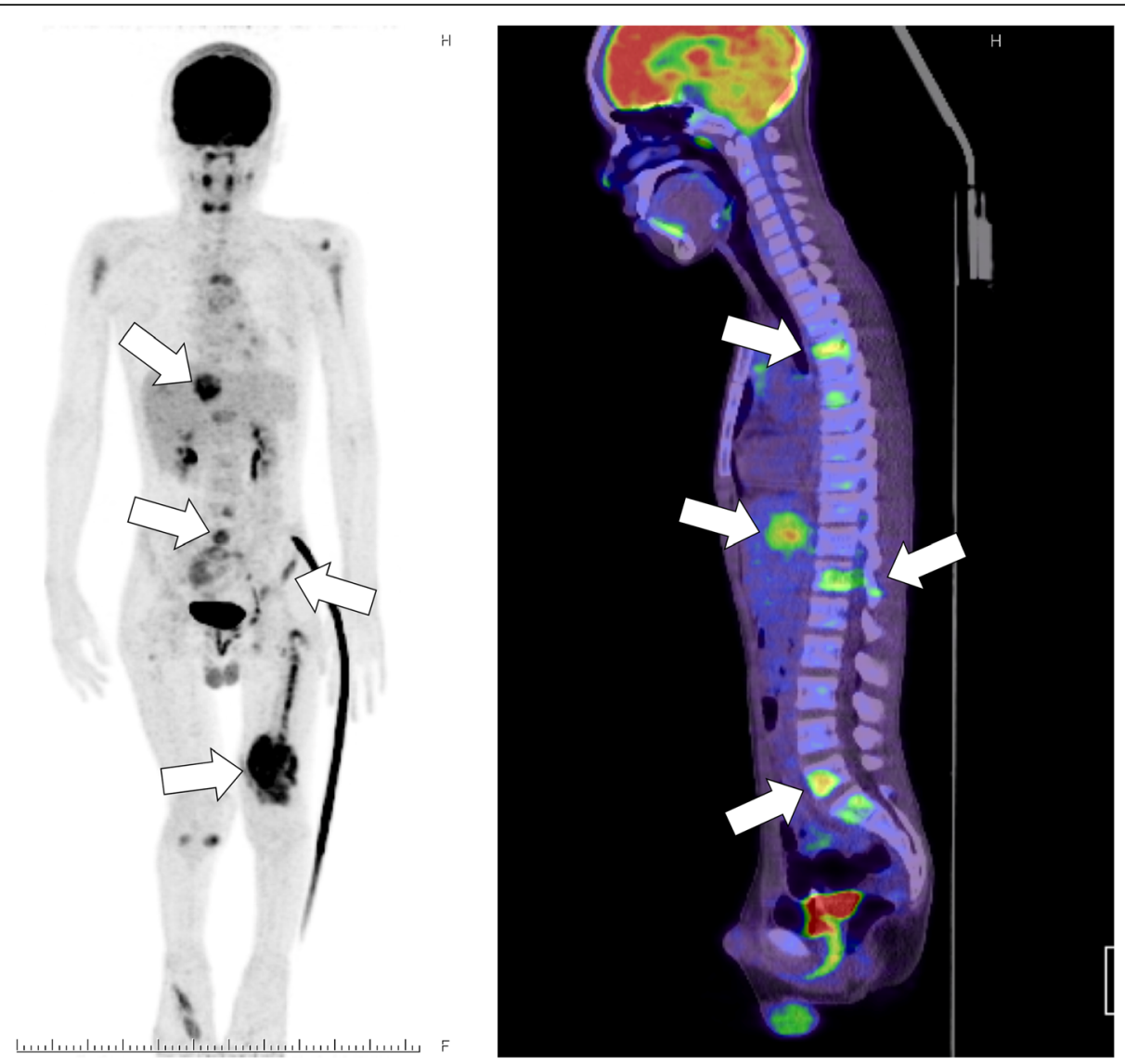

Fig. $6{ }^{18}$ Fluorine-labeled fluorodeoxyglucose-positron emission tomography. Multiple metastatic lesions were observed in the liver, spine, and pelvis 


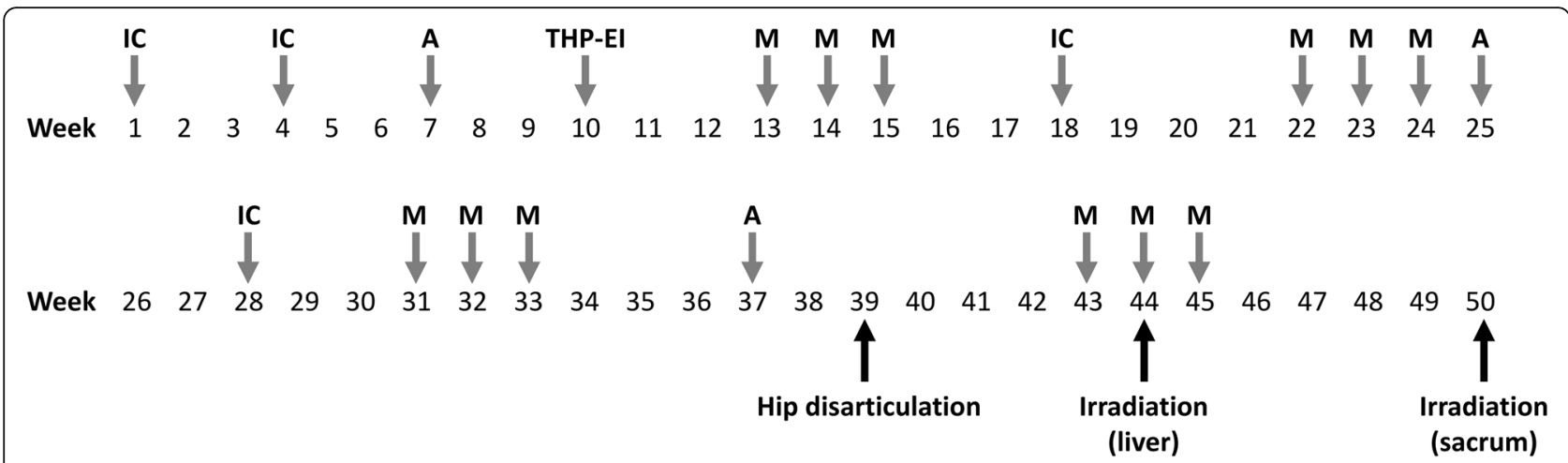

Fig. 7 Treatment courses. IC: ifosfamide $\left(2.65 \mathrm{~g} / \mathrm{m}^{2}\right.$ daily for 3 days) and carboplatin ( $560 \mathrm{mg} / \mathrm{m}^{2}$ on Day 1); THP-El: Pirarubicin (50 mg/m² on Day 1), etoposide ( $125 \mathrm{mg} / \mathrm{m}^{2}$ at Day 1 and Day 4$)$, and ifosfamide ( $1500 \mathrm{mg} / \mathrm{m}^{2}$ daily for 4 days); A: doxorubicin ( $25 \mathrm{mg} / \mathrm{m}^{2}$ daily for 3 days); M: methotrexate $\left(12 \mathrm{~g} / \mathrm{m}^{2}\right)$; A: doxorubicin $\left(30 \mathrm{mg} / \mathrm{m}^{2}\right.$ daily for 3 days)
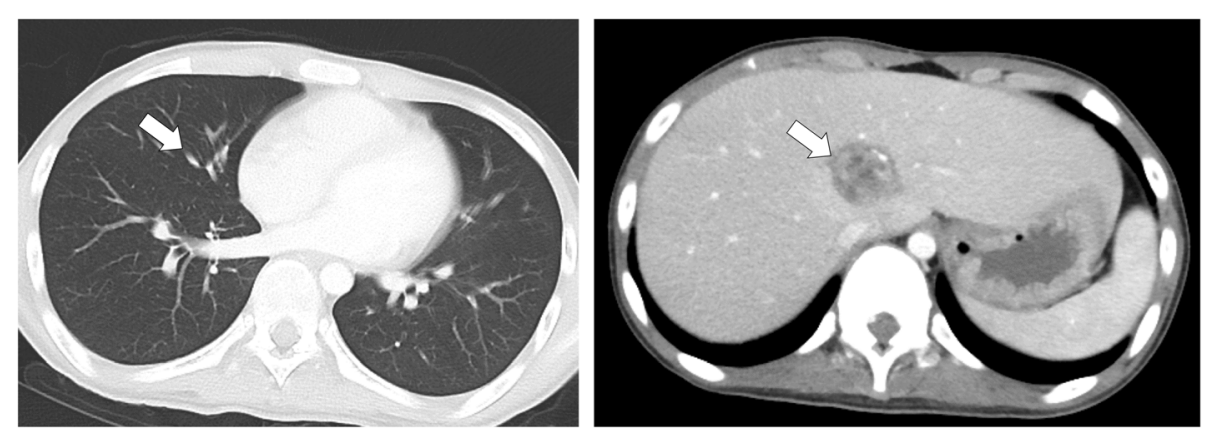

Fig. 8 Computed tomography $(C T)$ after chemotherapy. Reductions in the tumor volumes of metastatic lesions were observed in the lung and liver
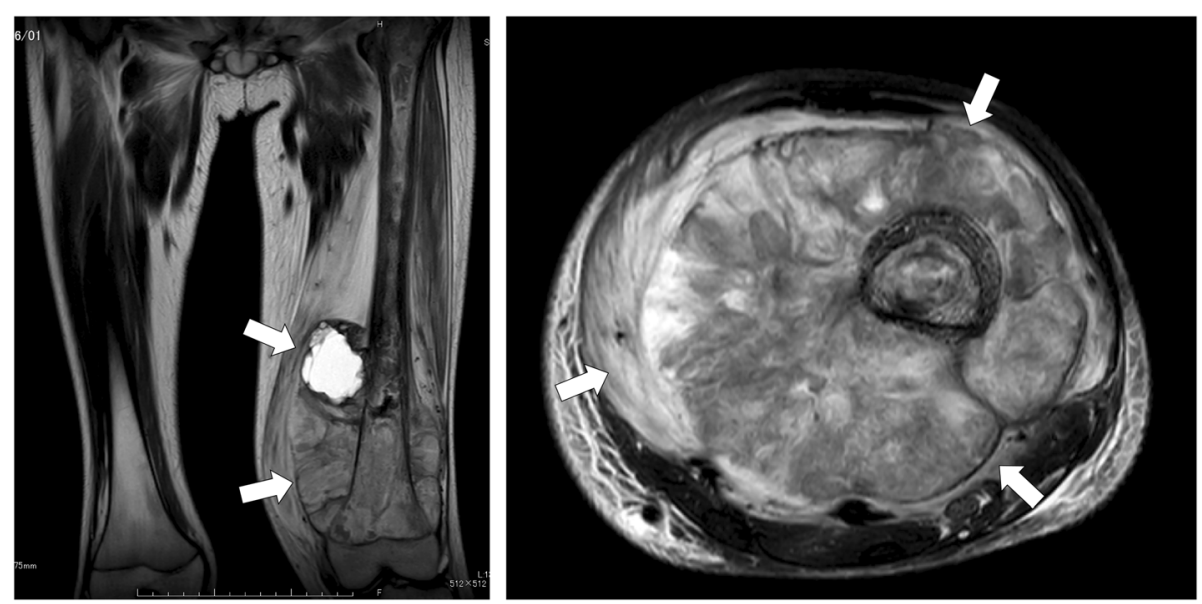

Fig. 9 Magnetic resonance imaging after chemotherapy. Significant increase in the tumor size was observed in the distal femur 


\section{Abbreviations}

${ }^{18} \mathrm{~F}$-FDG: ${ }^{18}$ Fluorine-labelled fluorodeoxyglucose; CT: Computed tomography; GFP: Green fluorescent protein; MRI: Magnetic resonance imaging; PET: Positron emission tomography

\section{Acknowledgments}

Not applicable.

\section{Authors' contributions}

All listed authors substantially contributed to the following aspects of the manuscript: SM, SY, HA, MK, SY, TO, and HT participated in diagnosing and treating the patient and in acquisition of data. SM, SY, HA, MK, SY, and TO collected the findings and drafted the manuscript. SM and HT revised the manuscript. All authors read and approved the final manuscript.

\section{Funding}

Not applicable.

\section{Availability of data and materials}

To protect privacy and respect confidentiality, no raw data have been made available in any public repository. The datasets used and/or analyzed during the current study available from the corresponding author on reasonable request.

\section{Ethics approval and consent to participate}

A family of the patient signed a letter of informed consent to allow his data to be stored, as required by Nagoya City University Hospital.

\section{Consent for publication}

Written informed consent was obtained from the patient and his parents for the publication of this case report and any accompanying images. A copy of the written consent form is available for review by the Editor of this journal.

\section{Competing interests}

The authors declare that they have no competing interests.

\section{Author details}

'Department of Orthopedic Surgery, Graduate School of Medical Science, Nagoya City University, Nagoya, Japan. ${ }^{2}$ Department of Orthopedic Surgery, Graduate School of Medical Science, Kanazawa University, Kanazawa, Japan. ${ }^{3}$ Department of Neonatology and Pediatrics, Graduate School of Medical Science, Nagoya City University, Nagoya, Japan.

Received: 10 June 2019 Accepted: 6 October 2019

Published online: 23 October 2019

\section{References}

1. Ottaviani G, Jaffe N. The epidemiology of osteosarcoma. Cancer Treat Res. 2009;152:3-13

2. Janeway KA, Grier HE. Sequelae of osteosarcoma medical therapy: a review of rare acute toxicities and late effects. Lancet Oncol. 2010;11(7):670-8.

3. Bernthal NM, Federman N, Eilber FR, Nelson SD, Eckardt JJ, Eilber FC, Tap WD. Long-term results ( $>25$ years) of a randomized, prospective clinical trial evaluating chemotherapy in patients with high-grade, operable osteosarcoma. Cancer. 2012;118(23):5888-93.

4. Rosen G, Nirenberg A. Neoadjuvant chemotherapy for osteogenic sarcoma: a five year follow-up (T-10) and preliminary report of new studies (T-12). Prog Clin Biol Res. 1985;201:39-51.

5. Rosen G. Preoperative (neoadjuvant) chemotherapy for osteogenic sarcoma: a ten year experience. Orthopedics. 1985;8(5):659-64.

6. Rosen G, Marcove RC, Caparros B, Nirenberg A, Kosloff C, Huvos AG. Primary osteogenic sarcoma: the rationale for preoperative chemotherapy and delayed surgery. Cancer. 1979;43(6):2163-77.

7. Liu ZL, Wang G, Peng AF, Luo QF, Zhou Y, Huang SH. Fatty acid synthase expression in osteosarcoma and its correlation with pulmonary metastasis. Oncol Lett. 2012;4(5):878-82.

8. Anninga JK, Gelderblom H, Fiocco M, Kroep JR, Taminiau AH, Hogendoorn PC, Egeler RM. Chemotherapeutic adjuvant treatment for osteosarcoma: where do we stand? Eur J Cancer. 2011;47(16):2431-45.

9. Grimer RJ. Surgical options for children with osteosarcoma. Lancet Oncol. 2005;6(2):85-92.
10. Ayerza MA, Farfalli GL, Aponte-Tinao L, Muscolo DL. Does increased rate of limb-sparing surgery affect survival in osteosarcoma? Clin Orthop Relat Res. 2010;468(11):2854-9.

11. Bielack SS, Kempf-Bielack B, Delling G, Exner GU, Flege S, Helmke K, Kotz R, Salzer-Kuntschik M, Werner M, Winkelmann W, et al. Prognostic factors in high-grade osteosarcoma of the extremities or trunk: an analysis of 1,702 patients treated on neoadjuvant cooperative osteosarcoma study group protocols. J Clin Oncol. 2002;20(3):776-90.

12. Wu PK, Chen WM, Lee OK, Chen CF, Huang CK, Chen TH. The prognosis for patients with osteosarcoma who have received prior manipulative therapy. J Bone Joint Surg Br. 2010;92(11):1580-5.

13. Wang JY, Wu PK, Chen PC, Yen CC, Hung GY, Chen CF, Hung SC, Tsai SF, Liu $\mathrm{CL}$, Chen TH, et al. Manipulation therapy prior to diagnosis induced primary osteosarcoma metastasis--from clinical to basic research. PLoS One. 2014; 9(5):e96571.

14. Cohen SP, Hooten WM. Advances in the diagnosis and management of neck pain. BMJ. 2017;358:3221.

15. Gross A, Langevin P, Burnie SJ, Bedard-Brochu MS, Empey B, Dugas E, FaberDobrescu M, Andres C, Graham N, Goldsmith CH, et al. Manipulation and mobilisation for neck pain contrasted against an inactive control or another active treatment. Cochrane Database Syst Rev. 2015;9:CD004249.

16. Furlan AD, Giraldo M, Baskwill A, Irvin E, Imamura M. Massage for low-back pain. Cochrane Database Syst Rev. 2015;9:CD001929.

17. Marletta G, Canfora A, Roscani F, Cernicchiaro L, Cutrera M, Russo M, Artioli G, Sarli L. The complementary medicine (CAM) for the treatment of chronic pain: scientific evidence regarding the effects of healing touch massage. Acta Biomed. 2015;86(Suppl 2):127-33.

18. Martin ML, Hernandez MA, Avendano C, Rodriguez F, Martinez H. Manual lymphatic drainage therapy in patients with breast cancer related lymphoedema. BMC Cancer. 2011;11:94.

19. Batalha LM, Mota AA. Massage in children with cancer: effectiveness of a protocol. J Pediatr. 2013;89(6):595-600.

20. Jane SW, Chen SL, Wilkie DJ, Lin YC, Foreman SW, Beaton RD, Fan JY, Lu MY, Wang YY, Lin YH, et al. Effects of massage on pain, mood status, relaxation, and sleep in Taiwanese patients with metastatic bone pain: a randomized clinical trial. Pain. 2011;152(10):2432-42.

21. Sarkar MR, Kinzl L. Use of tourniquet with or without Esmarch bandage. Orthop Traumatol. 1999;7(3):230-7.

22. Younger AS, Kalla TP, McEwen JA, Inkpen $\mathrm{K}$. Survey of tourniquet use in orthopaedic foot and ankle surgery. Foot Ankle Int. 2005;26(3):208-17.

23. Hayashi K, Jiang P, Yamauchi K, Yamamoto N, Tsuchiya H, Tomita K, Moossa AR, Bouvet M, Hoffman RM. Real-time imaging of tumor-cell shedding and trafficking in lymphatic channels. Cancer Res. 2007;67(17):8223-8.

\section{Publisher's Note}

Springer Nature remains neutral with regard to jurisdictional claims in published maps and institutional affiliations.

Ready to submit your research? Choose BMC and benefit from:

- fast, convenient online submission

- thorough peer review by experienced researchers in your field

- rapid publication on acceptance

- support for research data, including large and complex data types

- gold Open Access which fosters wider collaboration and increased citations

- maximum visibility for your research: over $100 \mathrm{M}$ website views per year

At BMC, research is always in progress.

Learn more biomedcentral.com/submissions 